\title{
PROFESSOR LOUIS J. POIRIER (1918-2014)
}

The Canadian neurological sciences community has lost one of its pioneers. Louis J. Poirier, a world-renowned brain anatomist and experimental neurologist, passed away peacefully on May 9, 2014, at age 95.

Born in Montreal on December 30, 1918, Poirier was trained as a medical doctor at the Université de Montréal, from which he received an MD degree in 1947. As a young medical doctor, he soon realized that, rather than diagnosing and curing diseases, what interested him most was the understanding of the pathophysiological mechanisms responsible for the appearance of such diseases, particularly those affecting the nervous system. Hence, instead of practicing clinical medicine, he immediately embarked into what was to be a long and highly fruitful journey in biomedical research. He started his career as a researcher by obtaining a $\mathrm{PhD}$ in neurobiology from the University of Michigan in 1950 after a series of brilliant studies on the anatomical organization of the temporal lobe in primates. These investigations were undertaken under the expert guidance of Professor Elizabeth C. Crosby, a world-renowned comparative neurologist. After the completion of his doctoral studies, the Université de Montréal offered him a position in the Histology Department of the Medical School, where he worked as both a teacher and a researcher from 1950 to 1964.

Soon after his arrival in Montreal, he set up an animal facility for macaque monkeys, which were to be his principal animal model throughout his career. He devoted his first research efforts to delineating the anatomical basis of the temporal lobe influence on respiration and cardiovascular activity in macaques. After having improved the Marchi tract-tracing method, he used it in collaboration with Claude Bertrand, then a young but already renowned neurosurgeon at the Hôpital Notre-Dame, to trace the spinothalamic and spinotectal tracts in both human and nonhuman primates. He then collaborated with Jean-Pierre Cordeau, who played a crucial role in the development of neuroscience in Montreal, to investigate the role of the hypothalamus on the responses to cold and immobilization in monkeys. At the beginning of the 1960s, Poirier became fascinated by the issue of midbrain dyskinesia, which was to become his major research interest for the rest of his career. He was one of the first researchers to exploit the stereotaxic electrolytic lesion approach to look for brain centers involved in the production of tremor. With the help of Cordeau and Herbert H. Jasper, he was able to detect electrophysiological correlates of tremor in the sensorimotor cortex of midbrain-lesioned monkeys. He then started to combine neuroanatomy, neurochemistry, and experimental neurology to unravel the brain mechanisms involved in the production of hypo- and hyperkinetic abnormal movements. While still in Montreal, Poirier initiated what was to become a highly fruitful collaboration with Theodor L. Sourkes, a neurochemist working at the Allan Memorial Psychiatric Institute at McGill University and who was already internationally known for his work on biogenic amines. In 1965, Poirier decided to move to the Université Laval in Quebec City, where he became Professor of Experimental Neurology, a position that gave him ample opportunity to pursue his research on brain mechanisms involved in the production of abnormal movements. It was in Quebec City that Poirier's career reached its peak. Soon after his arrival at the Université Laval, he founded the Neurobiology Research Center, which he headed until his retirement in 1985. In 1975, the Neurobiology Research Center moved to the Hôpital de l'Enfant-Jésus, the main neurology and neurosurgery center for most of the eastern part of Quebec. The Research Center rapidly acquired an international reputation, largely because of the development of one of the very first primate models of Parkinson's disease, which Poirier was able to produce with the help of René Boucher, his highly devoted research assistant. This model mimicked the motor symptoms of Parkinsonian patients in such a striking manner that it attracted to Quebec City famous neurologists, neurosurgeons, and neurobiologists from all over the world. The detailed histological and neurochemical investigation of this model undertaken by Poirier and Sourkes allowed them to demonstrate the existence of a direct relationship between the lesion of the neurons of the midbrain substantia nigra and the loss of striatal dopamine that characterizes Parkinson's disease. The publication of these results in the journal Brain in 1965 had a major impact on the orientation of research on Parkinson's disease, and became a citation classic. This pioneering study was followed by many other neuroanatomical, pharmacological, and neurochemical investigations that have shed a new light on the pathogenesis of movement disorders. Later in his career, Poirier made other important contributions to our knowledge of the organization of the primate basal ganglia. Among these are the demonstrations of striatal afferent and efferent with the help of radioactive neuronal markers; the tracing of serotoninergic, dopaminergic, noradrenergic, and cholinergic afferents to the basal ganglia; and the discovery of the embryonic origin of nigral neurons.

Besides his activities as a neuroscientist, Poirier also exerted remarkable leadership as a research administrator. He was a member 
of the Executive Committee of the Medical Research Council in Ottawa during more than a decade and he also acted as Head of the Fonds de Recherche du Québec, which has played and continues to play a crucial role in the development and maintenance of high-quality biomedical research in Quebec. Poirier received several prestigious distinctions in reconnaissance of his scientific and administrative achievements. For example, the Université de Rennes awarded him the title of doctor honoris causa (LL.D.) in 1973; he was enthroned as an Officer of the Order of Canada and received the Scientific Prize of the Quebec government in 1975; and the Canadian Council for the Arts attributed him the Killam Award in 1977. Furthermore, Poirier was elected an honorary member of several prestigious medical and scientific societies around the world.
For many of us, Poirier has been, above all, a remarkably capable, energetic, and humane mentor. He founded a highly original neuroscience school of thought that has attracted both researchers and clinicians from all parts of the world. In turn, these young neurologists, neurosurgeons, and neurobiologists helped disseminate his thoughts about the pathogenesis of motor disorders at the international level. His influence is at the basis of the tradition of excellence in neuroscience research that the Quebec scientific community has been fostering for more than 50 years.

André Parent

Department of Psychiatry and Neuroscience, Université Laval Quebec City, Canada Andre.Parent@fmed.ulaval.ca 